\title{
Effect of PCs superplasticizers on the rheological properties and hydration process of slag-blended cement pastes
}

\author{
M. Palacios · F. Puertas · P. Bowen • \\ Y. F. Houst
}

Received: 29 December 2008/ Accepted: 17 February 2009/Published online: 13 March 2009

(c) Springer Science+Business Media, LLC 2009

\begin{abstract}
The effect of polycarboxylate (PC) superplasticizers with different structure on the rheological properties and hydration process of slag-blended cement pastes with a slag content between 0 and $75 \%$ has been studied. Fluidizing properties of PCs admixtures are significantly higher in slag-blended cement with respect to non-blended Portland cement. Also, it has been observed that the rise of the fluidity induced by the PCs on the cement pastes increases with the slag content. This effect is mainly attributed to a decrease in the amount of $\mathrm{C}_{3} \mathrm{~A}$ available to adsorb and consume admixture to form an organo-mineral phase. Consequently, the PC admixtures are absorbed onto the silicate phases of the clinker and onto the slag particles, inducing a repulsion and the concomitant reduction in yield stress despite a reduction in the zeta potential. The rheological results allow us to conclude that the highest increase of the fluidity is caused by the admixtures with highest molecular weight due to the higher steric repulsion induced. As a consequence of the adsorption of the PCs, a delay of the hydration process of the pastes has been observed.
\end{abstract}

\section{Introduction}

The use of mineral additions, as a partial substitution of Portland cement clinker, has become one of the chief ways

M. Palacios $(\square)$. F. Puertas

Eduardo Torroja Institute for Construction Science (CSIC), Box 19002, 28080 Madrid, Spain

e-mail: martapalacios@ietcc.csic.es

P. Bowen · Y. F. Houst

Laboratoire de technologie des poudres, École Polytechnique

Fédérale de Lausanne (EPFL), 1015 Lausanne, Switzerland of obtaining more eco-efficient cements, whose manufacture entails lower energy demands and lower emission of greenhouse gas into the atmosphere than ordinary Portland cement (OPC). Both natural additions such as volcanic ash or limestone and industrial by-products such as fly ash or blast furnace slag are appropriate for these purposes.

The advantages of slag-blended cements include not only the energy savings and lower pollution compared to clinker production, but also greater mechanical strength at longer ages [1] and higher durability than non-blended Portland cement due to their finer pore structure [2]. More specifically, these cements are highly sulphate- [3] and alkali-aggregate reaction- [4] resistant, while exhibiting a lower chloride diffusion rate [2] than OPC. However, slagblended cements also show poor early strength and lower resistance against carbonation than non-blended Portland cements. Slag cements also have lower heat of hydration values than OPC and the reaction processes involved in their hydration are more complex $[5,6]$. In these cements, the $\mathrm{Ca}(\mathrm{OH})_{2}$ released as a result of $\mathrm{C}_{3} \mathrm{~S}$ hydration activates the slag hydration.

Superplasticizers are nowadays an essential component of concrete. These admixtures reduce the amount of water needed in the preparation of concrete, enhancing its mechanical strength and durability. The use of the latest generation polycarboxylate (PC)-based superplasticizers, which induces the highest reduction of water content, has become imperative in high performance and self-compacting concretes. These PC admixtures are characterized by a "comb" type structure [7] in which the backbone is a linear hydrocarbonate chain and carboxylate and ether groups form the lateral chains. In a process mediated by the carboxylate groups, these admixtures are adsorbed onto the cement particles, which are subsequently dispersed due to the electrosteric repulsion generated [8,9]. A number of 
papers [10-12] have confirmed that the flowability induced by PC admixtures depends directly on the structure of these admixtures (length of the main and lateral chains, density of lateral ether groups, molecular weight and molecular weight distribution). As a general rule, the longer and more numerous the ether "teeth", the greater and longer-lasting is the flowability induced by the admixture. However, there is an optimum density of the lateral chains that origins the highest increase of the fluidity. In addition, the ratio between the number of carboxylate groups (main chain constituents) and the number of ether groups (lateral chain constituents) is a fundamental parameter, increasing the fluidity slightly when this ratio is low (0.057) [10].

Nonetheless, the dispersive effect of superplasticizers and specifically of polycarboxyalate-based admixtures also depends on cement properties. Many authors have concluded that the fluidizing effect of PC admixtures depends on factors such as $\mathrm{C}_{3} \mathrm{~A}$ content, type and content of calcium sulphate used as a setting regulator [13], clinker alkali content [14], specific surface and particle size distribution [15] and type of mineral addition. Nonetheless, very few papers have been published on this latter factor, namely the effect of additions on the fluidizing properties of PC-based admixtures. According to some reports $[10,16]$, the effect of the admixture on CEM II/A-V and CEM II/B-L cement pastes is similar to the changes induced in addition-free cement pastes. By contrast, the inclusion of only $0.1 \%$ of PC-based admixtures in CEM III/B cement (with around $72 \%$ slag by cement weight) led to cement segregation [10, 16]. Consequently, slag cements obviously require lower dosages of such admixtures than non-blended Portland cement to attain similar increases in flowability. The causes of this differential behaviour have yet to be established, despite the need for such studies to avoid problems of incompatibility.

The present paper aims to elucidate the lower superplasticizer demand seen for slag-blended cements. This is performed by investigating the zeta potential and the rheological properties of cements with varying percentages of slag $(0-75 \%)$. The effect of such admixtures on cement hydration processes is also discussed.

\section{Experimental}

\section{Materials}

Five cements with different content of slag have been used. Cements $\mathrm{C} 1, \mathrm{C} 4$ and $\mathrm{C} 5$ were commercial products, whereas cements $\mathrm{C} 2$ and $\mathrm{C} 3$ were obtained by blending cement $\mathrm{C} 1$ with the specified proportion of Spanish blast furnace slag (S1). The chemical and mineralogical composition found by Rietveld analysis [17] of the different
Table 1 Cement and slag chemical composition and BET specific surface

\begin{tabular}{lllllll}
\hline & $\mathrm{C} 1$ & $\mathrm{C} 2$ & $\mathrm{C} 3$ & $\mathrm{C} 4$ & $\mathrm{C} 5$ & $\mathrm{~S} 1$ \\
\hline \% slag & 0 & 10 & 28 & 54 & 75 & 100 \\
L.O.I. & 0.43 & 0.58 & 1.32 & 1.37 & 1.65 & 2.72 \\
$\mathrm{SiO}_{2}$ & 18.61 & 18.84 & 23.75 & 24.14 & 27.86 & 35.34 \\
$\mathrm{Al}_{2} \mathrm{O}_{3}$ & 4.46 & 4.84 & 6.09 & 8.23 & 9.75 & 13.65 \\
$\mathrm{Fe}_{2} \mathrm{O}_{3}$ & 4.39 & 4.22 & 3.70 & 2.61 & 2.03 & 0.39 \\
$\mathrm{CaO}$ & 65.03 & 62.92 & 58.40 & 53.50 & 47.30 & 41.00 \\
$\mathrm{MgO}$ & 2.20 & 2.68 & 3.79 & 5.64 & 6.86 & 4.11 \\
$\mathrm{Sulphates}$ & 2.94 & 2.62 & 2.03 & 1.85 & 1.00 & 0.06 \\
$\mathrm{Sulphides}$ & - & 0.08 & 0.63 & 0.53 & 1.04 & 1.91 \\
$\mathrm{I} . \mathrm{R}$. & 0.18 & 0.52 & 0.16 & 0.72 & 2.70 & 0.64 \\
$\mathrm{Na} 2 \mathrm{O}$ & 0.12 & 0.18 & 0.26 & 0.14 & 0.18 & 0.01 \\
$\mathrm{~K}_{2} \mathrm{O}$ & 0.48 & 0.63 & 0.70 & 0.29 & 0.21 & - \\
$\mathrm{CaO}$ free & 0.64 & 0.64 & 0.72 & 0.52 & 0.34 & - \\
Specific surface Blaine & 430 & 384 & 394 & 436 & 408 & 325 \\
$\quad\left(\mathrm{~m}^{2} / \mathrm{kg}\right)$ & & & & & & \\
$\mathrm{Specific} \mathrm{surface} \mathrm{BET}$ & 1.09 & 1.04 & 1.01 & 1.18 & 0.88 & 1.03 \\
$\quad\left(\mathrm{~m}^{2} / \mathrm{g}\right)$ & & & & & & \\
\hline
\end{tabular}

L.O.I. loss on ignition, I.R. insoluble residue

cements are shown in Tables 1 and 2. Characteristic particle diameters (volume based) are reported in Table 3 of the cements and slag, measured using laser diffraction (MALVERN MASTERSIZER S) dispersed in isopropanol.

The physical-chemical characteristics of the six commercial PC admixtures used are given in Table 4. The quantity and type of functional groups were characterized as described in the literature [18, 19].

Tests conducted

Determination of the effect of PC-based superplasticizers on the zeta potential of slag cement suspensions

The effect of different dosages of superplasticizer on the zeta potential of cement suspensions was determined with a Colloidal Dynamics Acoustosizer IIs. Cements and slag were previously milled and sieved to have a particle size smaller than $20 \mu \mathrm{m}$ (approximately the upper size limit for zeta potential measurement using electroacoustics). Sieved binders then were homogenized to ensure representative samples. Cement suspensions were prepared by mixing $30 \mathrm{~g}$ of binder with $160 \mathrm{~g}$ of water (solid fraction in the suspension $=0.16$ ). After stirring for $15 \mathrm{~min}$ in a magnetic stirrer, the suspensions were placed in a sonicator for $5 \mathrm{~min}$ and then in the measuring cell to determine their zeta potential, approximately $25 \mathrm{~min}$ after contact with water. PC admixture dosages ranging from 0 to $5 \mathrm{mg}$ polymer/g cement (with respect to dry admixture content) were added to these suspensions using an automatic titrator. The zeta 
Table 2 Cement mineralogical composition

n.d. non detected

$\mathrm{C}_{3} \mathrm{~S}=$ tricalcium silicate;

$\mathrm{C}_{2} \mathrm{~S}=$ bicalcium silicate,

$\mathrm{C}_{3} \mathrm{~A}=$ tricalcium aluminate;

$\mathrm{C}_{4} \mathrm{AF}=$ tetracalcium

ferroaluminate

\begin{tabular}{lrrrrr}
\hline Phase & \multicolumn{1}{c}{$\mathrm{C} 1$} & \multicolumn{1}{c}{$\mathrm{C} 2$} & \multicolumn{1}{c}{$\mathrm{C} 3$} & \multicolumn{1}{l}{$\mathrm{C} 4$} & \multicolumn{1}{c}{ C5 } \\
\hline $\mathrm{C}_{3} \mathrm{~S}$ & $70.8( \pm 0.4)$ & $69.4( \pm 0.4)$ & $40.9( \pm 0.4)$ & $34.0( \pm 0.4)$ & $19.1( \pm 0.4)$ \\
$\mathrm{C}_{2} \mathrm{~S}$ & $10.3( \pm 0.4)$ & $12.5( \pm 0.4)$ & $11.8( \pm 0.8)$ & $1.2( \pm 0.2)$ & $0.5( \pm 0.2)$ \\
$\mathrm{C}_{3} \mathrm{~A}$ & $2.7( \pm 0.1)$ & $2.8( \pm 0.1)$ & $1.8( \pm 0.1)$ & $1.2( \pm 0.1)$ & $0.7( \pm 0.2)$ \\
$\mathrm{C}_{4} \mathrm{AF}$ & $13.6( \pm 0.2)$ & $13.0( \pm 0.1)$ & $8.0( \pm 0.1)$ & $5.8( \pm 0.2)$ & $3.2( \pm 0.2)$ \\
$\mathrm{K}_{2} \mathrm{SO}_{4}$ & $0.6( \pm 0.1)$ & \multicolumn{1}{c}{ n.d. } & n.d. & $0.4( \pm 0.1)$ & $0.3( \pm 0.1)$ \\
$\mathrm{CaSO}_{4} \cdot 1 / 2 \mathrm{H}_{2} \mathrm{O}$ & $1.1( \pm 0.1)$ & $0.8( \pm 0.1)$ & $1.0( \pm 0.1)$ & n.d. & n.d. \\
$\mathrm{CaSO}_{4}$ & $0.9( \pm 0.1)$ & $1.5( \pm 0.1)$ & $0.8( \pm 0.1)$ & $2.8( \pm 0.2)$ & $1.5( \pm 0.2)$ \\
\hline
\end{tabular}

Cement paste rheology was measured with a Haake Rheowin Pro RV1 viscosimeter having concentric cylinders and roughened surfaces coaxial rotor. The following sequence was followed: initially the shear rate was kept constant at $100 \mathrm{~s}^{-1}$ for $1 \mathrm{~min}$, ramped upwards from 0 to $100 \mathrm{~s}^{-1}$ over $12 \mathrm{~min}$ and then reduced from 100 to $10 \mathrm{~s}^{-1}$ over $12 \mathrm{~min}$. Three tests were carried out on each cement pastes.

\section{Isothermal conduction calorimetry}

The measurements were recorded with a TAM Air conduction calorimeter on cement pastes with a w/c ratio of 0.40 . Five grams of cement and $2 \mathrm{~g}$ of water (with or without admixture) were mixed into a flask with a spatula for $3 \mathrm{~min}$. The flask was then closed and placed into the calorimeter. The dosage used to study the effect of PCbased admixtures on cement paste hydration processes was 0.5 and $1.0 \mathrm{mg}$ polymer/g cement. The cumulative heat was then recorded during $80 \mathrm{~h}$ calculated using standard TAM Air software. As the sample was mixed externally, the first $30 \mathrm{~min}$ were not considered.

Table 4 Physical and chemical characteristics of the polycarboxylate-based admixtures

\begin{tabular}{|c|c|c|c|c|c|c|}
\hline Admixture & PC-1 & PC-2 & PC-3 & PC-4 & PC-5 & PC-6 \\
\hline Solids content (\%) & 35.3 & 38.8 & 20.4 & 23.4 & 24.1 & 19.9 \\
\hline $\mathrm{pH}$ & 4.6 & 4.3 & 8.0 & 6.5 & 6.0 & 7.0 \\
\hline Density $\left(\mathrm{g} / \mathrm{cm}^{3}\right)$ & 1.1 & 1.1 & 1.0 & 1.0 & 1.0 & 1.0 \\
\hline $\begin{array}{l}\text { Rotational viscosity at } \\
\qquad 100 \mathrm{~s}^{-1}, 25{ }^{\circ} \mathrm{C}(\mathrm{mPa} \mathrm{s})\end{array}$ & 57.6 & 145.4 & 38.0 & 75.3 & 55.6 & 39.4 \\
\hline \multirow{3}{*}{$\begin{array}{l}\text { Molecular weight (main peaks } \\
\text { determined by GPC) (Da) }\end{array}$} & \multirow[t]{3}{*}{9,700} & 160,000 & 64,600 & 46,000 & 28,000 & \multirow[t]{3}{*}{17,600} \\
\hline & & 30,000 & 12,100 & 13,000 & 6,900 & \\
\hline & & 1,300 & & 3,600 & & \\
\hline$\% \mathrm{C}$ & 52.0 & 52.5 & 49.5 & 51.2 & 52.1 & 50.0 \\
\hline$\%$ Esthers & 26.4 & 28.7 & 14.0 & 6.0 & 7.5 & 13.6 \\
\hline$\%$ Carboxylate salts & 8.5 & n.d. & 28.0 & 21.4 & 18.5 & 32.1 \\
\hline$\%$ Ethers & 66.4 & 71.3 & 57.9 & 72.5 & 74.0 & 54.3 \\
\hline$\%$ Carboxylate salts $\%$ ethers & 0.13 & n.d. & 0.48 & 0.29 & 0.25 & 0.59 \\
\hline
\end{tabular}

n.d. non detected 


\section{Results and discussion}

Effect of polycarboxylate-based superplasticizers on the zeta potential of slag cement suspensions

Table 5 shows the zeta potential of the five cements and slag suspensions. From these results, it is observed that the zeta potential of the cement suspensions in the absence of admixtures is slightly more positive with increasing slag content. The zeta potential of cement $\mathrm{C} 1$ suspensions was $+0.2 \mathrm{mV}$ and increased to $+1.3 \mathrm{mV}$ in cement $\mathrm{C} 5$. The slag suspension presents an expected negative zeta potential $(-2.7 \mathrm{mV})[20]$.

A very slight decline in the zeta potential was observed with the inclusion of PC admixtures, to values close to $0 \mathrm{mV}$ (see Fig. 1). Since all admixtures induce a significant reduction in yield stress, theses results show clearly that steric mechanisms prevail over the electrostatic effect in the repulsion induced [8, 21]. At dosages higher than $0.5 \mathrm{mg}$ admixture $/ \mathrm{g}$ binder, the zeta potential remained constant.

Why the blended cements have a more positive zeta potential as the slag increases is unclear. Also the behaviour of the neat slag with the PCs is difficult to interpret. For certain cases, there is a slight decrease in zeta potential as the PC dosage is increased, as expected if the negatively charged PCs adsorbs onto the slag particles (e.g. PC1). For other PCs (PC2, PC4 and PC5), there is a significant decrease in magnitude of the zeta potential as the PC dosage is increased. This could be due to a change in surface charge density induced by the adsorption of the PCs also postulated by Zingg et al. [22] when observing similar behaviour. Thus, a possible explanation in both of the above cases is a modification of the composition of the ionic double layer as a function of slag/cement ratio and type of adsorbed PC. Interpretation of zeta potentials of cementitious materials is complicated as recently highlighted by Zingg et al. [22] where positive zeta potentials for the silicate phase are measured when silicates are expected to be negative in basic media. The authors proposed a qualitative model linked to specific adsorption of potential determining ions in the Stern layer. In particular, the adsorption of $\mathrm{Ca}^{2+}$, which would reduce the slag potential towards zero and increase the positive value of the cement potential. However further investigations are needed to better elucidate this behaviour, both (1) by

Table 5 Zeta potential of cement and slag supensions

\begin{tabular}{lcrrrrr}
\hline Binder & $\mathrm{C} 1$ & $\mathrm{C} 2$ & $\mathrm{C} 3$ & $\mathrm{C} 4$ & $\mathrm{C} 5$ & \multicolumn{1}{c}{$\mathrm{S} 1$} \\
\hline Zeta potential $(\mathrm{mV})$ & +0.2 & +0.7 & +0.5 & +1.0 & +1.3 & -2.7 \\
$\mathrm{pH}$ & 12.5 & 12.2 & 12.2 & 12.2 & 12.0 & 11.0 \\
\hline
\end{tabular}

investigating slag in pore solutions with $\mathrm{Ca}^{2+}$ concentrations closer to that found in OPC pore solution and (2) atomistic simulations of the near surface layers as demonstrated by the Group of Parker [23]. These studies were made on goethite surfaces where the finite size of ions and solvent interactions seem to dominate electrostatic interactions for high concentrations of electrolytes.

\section{Rheological behaviour}

Figure 2 shows the hysteresis cycles for the cement pastes with different proportions of slag.

In the hysteresis cycles for the cement pastes $\mathrm{C} 1, \mathrm{C} 2$ and C3, the decline curve fell below that of increasing shear rate. However, with increasing slag content the area of the hysteresis cycle decreased considerably, with the curves for shear rate increase and decline overlapping in the $\mathrm{C} 3$ pastes. On the contrary, in hysteresis cycles for $\mathrm{C} 4$ and $\mathrm{C} 5$ pastes (54\% and $75 \%$ slag, respectively), shear rate decline curve was positioned above the increase curve. Such behaviour implies that the interaction between the particles was higher than the shear stress exerted by the rotor and that disruption of agglomerates would need a greater force [24]. This result also implies that the interparticle forces between slag particle is greater than between the cement particles as at $75 \%$ slag the most frequently encountered particle pairs should be slag-slag interactions. These results are consistent with the yield stress results presented in the next section.

The shear rate decline curves were analyzed to determine the rheological parameters of the cement pastes. In all cases, these curves could be fitted to a straight line defined by the Bingham equation (see Eq. 1), whose $y$-intercept is associated with the yield stress and its slope with the plastic viscosity of the pastes.

$\tau=\tau_{0}+\mu \dot{\gamma}$

A comparison of the yield stress for the various cement pastes without admixture (see Table 6) showed that this rheological parameter rose with increasing slag content; in other words, the interaction forces among the agglomerates formed increased [25] as postulated above. By contrast, the plastic viscosity values were similar for the five cements studied, indicating that the size and number of agglomerates formed was likewise similar in all cases and the viscosity measurement is perhaps less sensitive and shows a higher experimental variation.

Figure 3 and Table 7 show the variation in cement paste yield stress and plastic viscosity, respectively, in the presence of PC-based admixtures. According to the results obtained, the fluidizing effect induced by such admixtures depended on the dosage and type of admixture and the percentage of slag in the cement. 

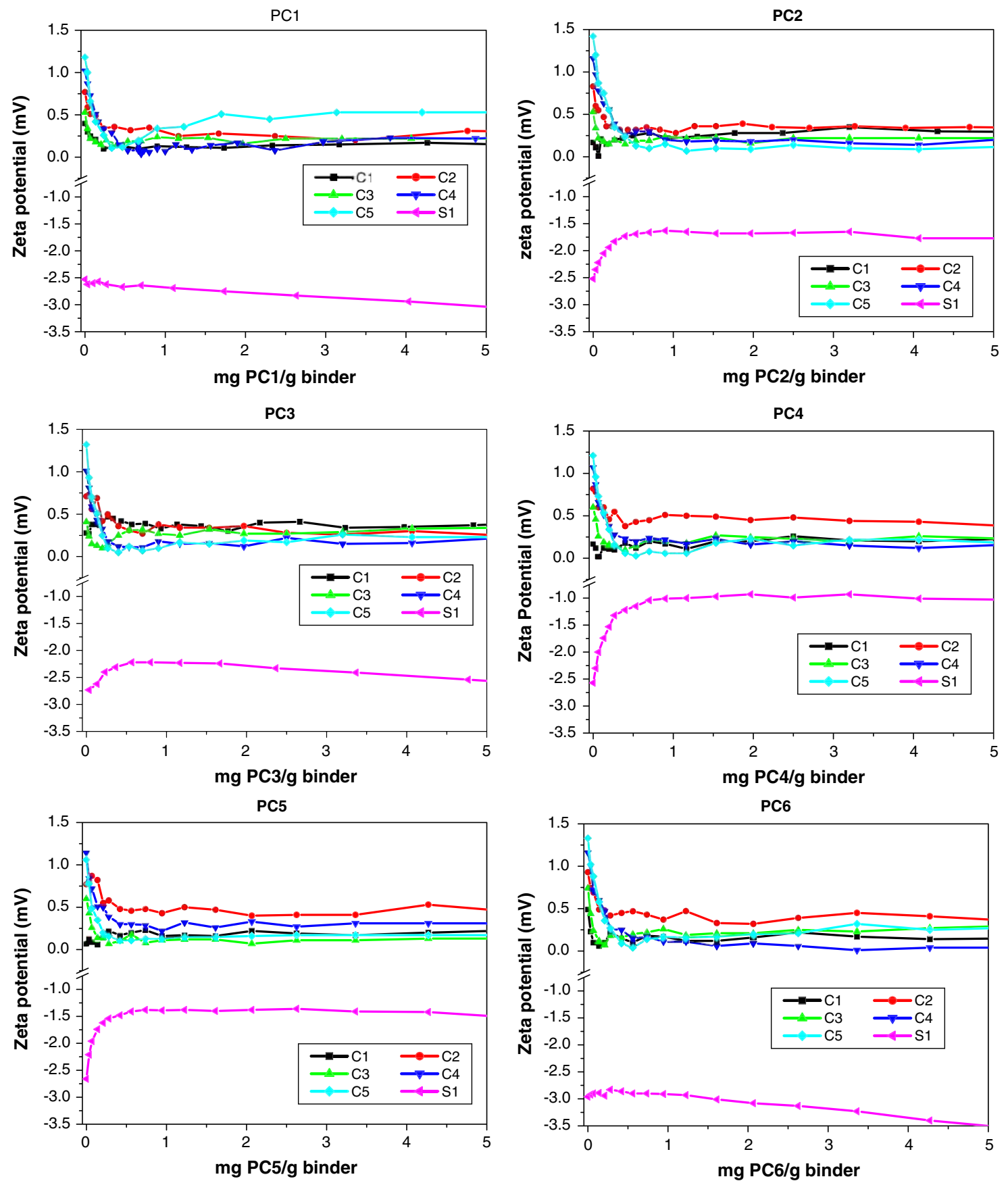

Fig. 1 Evolution of zeta potential of cement suspensions in presence of polycarboxylate-based admixtures

An increase in admixture dosage gave a decline in yield stress and concomitantly an increase in flowability in all the cement pastes. Of the six admixtures used, PC2, PC3 and PC4 induced the greatest decline in yield stress (see Fig. 3). Moreover, dosages of PC4 over $0.75 \mathrm{mg} / \mathrm{g}$ binder produced segregation in all cement pastes studied. As indicated from the zeta potential curves shown in Fig. 2, the admixtures generate a steric repulsion. Consequently, the more effective fluidization generated by
PC2, PC3 and PC4 can be associated with the greater induced steric repulsion. This can be related to their higher molecular weight (see Table 4), which should induce an increase in the adsorbed layer thickness [2628]. However, it is observed that in cement pastes with the highest slag content (C4 and C5), low dosages of PC6 $(0.25-0.50 \mathrm{mg} / \mathrm{g}$ binder $)$, despite its lower molecular weight, induces a similar decrease of yield stress to PC2, PC3 and PC4. 
Fig. 2 Hysteresis cycles of cement pastes
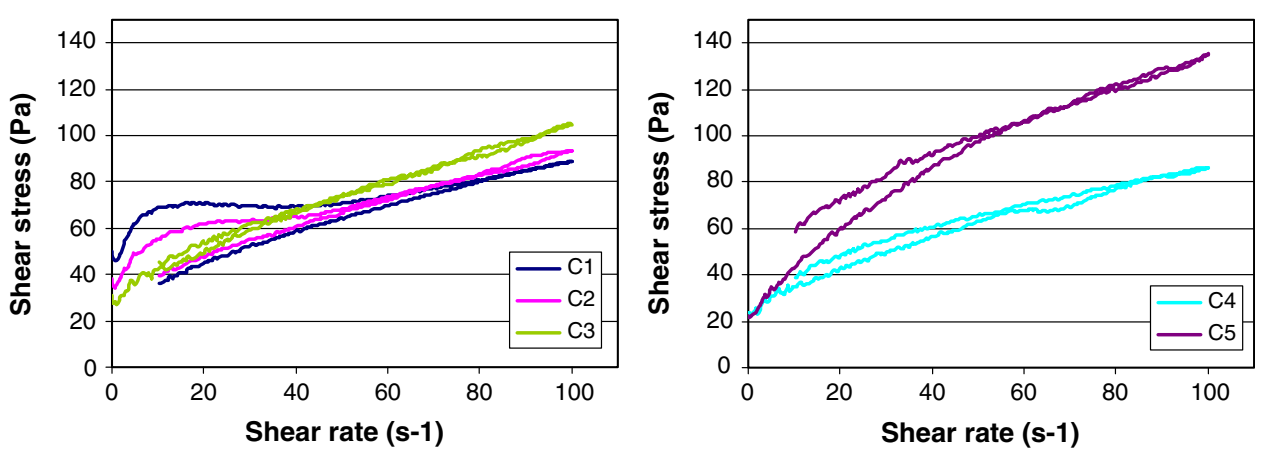

Table 6 Rheological parameters (yield stress and plastic viscosity) of cement pastes

\begin{tabular}{|c|c|c|c|c|c|}
\hline Cement & $\mathrm{C} 1$ & $\mathrm{C} 2$ & $\mathrm{C} 3$ & $\mathrm{C} 4$ & $\mathrm{C} 5$ \\
\hline Yield stress $(\mathrm{Pa})$ & $36.5( \pm 1.9)$ & $36.8( \pm 1.0)$ & $58.0( \pm 2.7)$ & $55.2( \pm 4.0)$ & $62.4( \pm 2.9)$ \\
\hline Plastic viscosity ( $\mathrm{Pa} \mathrm{s}$ ) & $0.62( \pm 0.05)$ & $0.55( \pm 0.03)$ & $0.77( \pm 0.08)$ & $0.66( \pm 0.02)$ & $0.74( \pm 0.07)$ \\
\hline
\end{tabular}
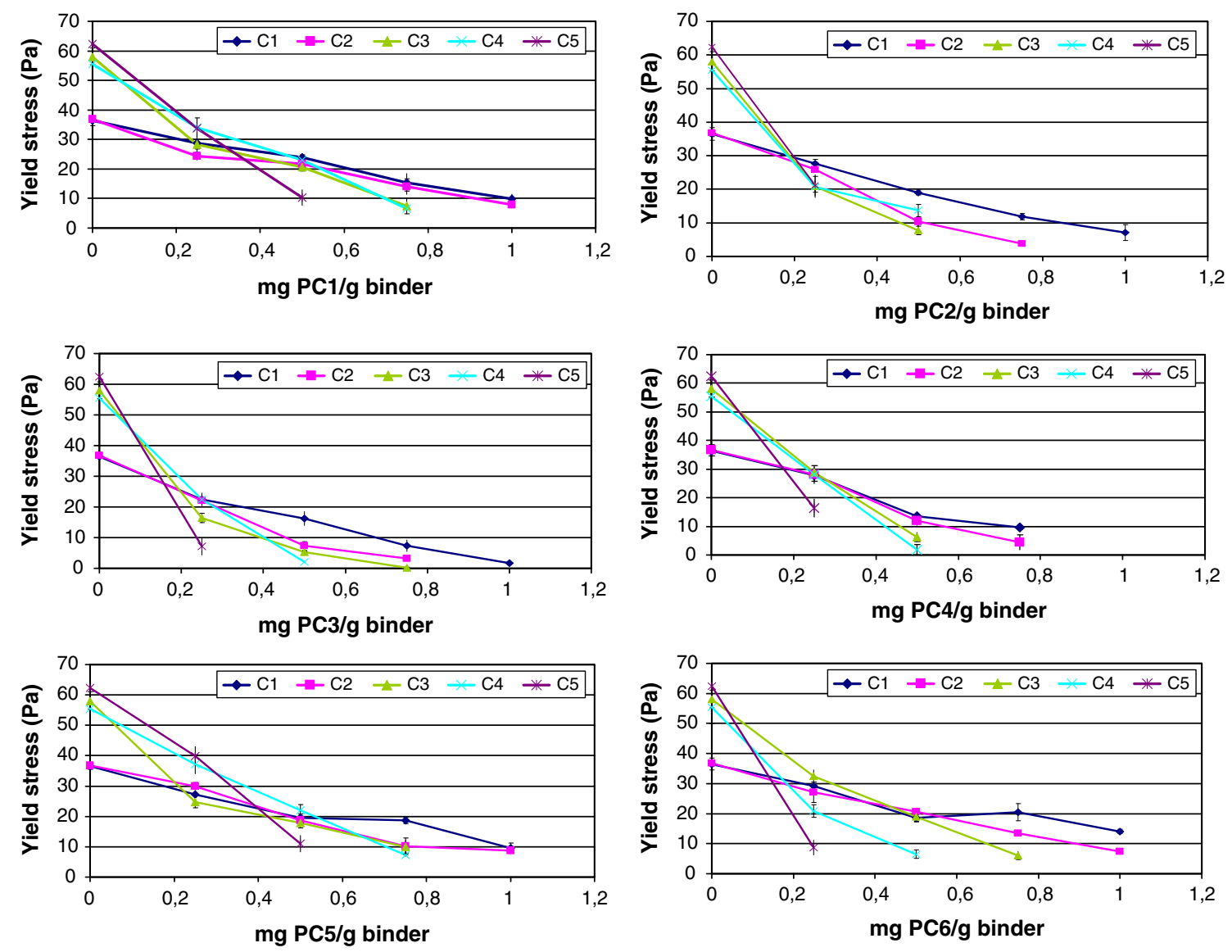

Fig. 3 Evolution of yield stress in cement pastes in presence of polycarboxylate-based admixtures

As Fig. 3 shows, the decline in yield stress of cement pastes caused by the admixtures increases with the percentage of slag. Indeed, whereas in cement $\mathrm{C} 1$ dosages of only $0.25 \mathrm{mg} / \mathrm{g}$ cement lowered yield stress by $21-38 \%$, this same dose reduced that parameter by up to $88 \%$ in cement pastes C5 (with a slag content of 75\%). Similarly, dosages of over $0.5 \mathrm{mg}$ polymer/g binder caused segregation in all $\mathrm{C} 5$ cement pastes, and even segregation is observed is these cement pastes when dosages of PC2, PC3, PC4 and PC6 higher than $0.25 \mathrm{mg}$ polymer/g binder 
Table 7 Evolution of plastic viscosity in cement pastes in presence of polycarboxylate based admixtures

\begin{tabular}{|c|c|c|c|c|c|c|}
\hline \multirow[t]{2}{*}{ Binder } & \multirow[t]{2}{*}{ Admixture } & \multicolumn{5}{|c|}{ mg admixture/g binder } \\
\hline & & 0 & 0.25 & 0.5 & 0.75 & 1.0 \\
\hline \multirow[t]{6}{*}{$\mathrm{C} 1$} & PC1 & 0.62 & 0.55 & 0.64 & 0.69 & 0.64 \\
\hline & PC2 & 0.62 & 0.71 & 0.67 & 0.54 & 0.55 \\
\hline & PC3 & 0.62 & 0.66 & 0.57 & 0.51 & 0.35 \\
\hline & PC4 & 0.62 & 0.59 & 0.57 & 0.65 & - \\
\hline & PC5 & 0.62 & 0.65 & 0.62 & 0.76 & 0.67 \\
\hline & PC6 & 0.62 & 0.73 & 0.65 & 0.64 & 0.61 \\
\hline \multirow[t]{6}{*}{$\mathrm{C} 2$} & PC1 & 0.55 & 0.68 & 0.67 & 0.62 & 0.68 \\
\hline & $\mathrm{PC} 2$ & 0.55 & 0.70 & 0.60 & 0.59 & - \\
\hline & PC3 & 0.55 & 0.77 & 0.60 & 0.36 & - \\
\hline & PC4 & 0.55 & 0.51 & 0.61 & 0.62 & - \\
\hline & PC5 & 0.55 & 0.69 & 0.71 & 0.71 & 0.72 \\
\hline & PC6 & 0.55 & 0.63 & 0.78 & 0.74 & 0.58 \\
\hline \multirow[t]{6}{*}{ C3 } & PC1 & 0.77 & 0.72 & 0.63 & 0.62 & - \\
\hline & PC2 & 0.77 & 0.65 & 0.54 & - & - \\
\hline & PC3 & 0.77 & 0.82 & 0.41 & 0.36 & - \\
\hline & PC4 & 0.77 & 0.68 & 0.57 & - & - \\
\hline & PC5 & 0.77 & 0.65 & 0.65 & 0.56 & - \\
\hline & PC6 & 0.77 & 0.75 & 0.89 & 0.57 & - \\
\hline \multirow[t]{6}{*}{$\mathrm{C} 4$} & PC1 & 0.65 & 0.59 & 0.52 & 0.42 & - \\
\hline & PC2 & 0.65 & 0.61 & 0.47 & - & - \\
\hline & PC3 & 0.65 & 0.57 & 0.29 & - & - \\
\hline & PC4 & 0.65 & 0.52 & 0.46 & - & - \\
\hline & PC5 & 0.65 & 0.60 & 0.55 & 0.48 & - \\
\hline & PC6 & 0.65 & 0.64 & 0.43 & - & - \\
\hline \multirow[t]{6}{*}{ C5 } & PC1 & 0.74 & 0.75 & 0.60 & - & - \\
\hline & PC2 & 0.74 & 0.63 & - & - & - \\
\hline & PC3 & 0.74 & 0.52 & - & - & - \\
\hline & PC4 & 0.74 & 0.62 & - & - & - \\
\hline & PC5 & 0.74 & 0.92 & 0.44 & - & - \\
\hline & PC6 & 0.74 & 0.86 & - & - & \\
\hline
\end{tabular}

are used. Alonso et al. and Puertas et al. [10, 16] reported in an earlier paper that $\mathrm{PC}$ admixtures had a greater dispersive effect on slag cement than on slag-free Portland cement pastes.

The main reason for the differential lowering of cement paste yield stress by the superplastizers can therefore be linked to the variation in the mineralogical composition of the cements themselves. In the slag-free cement pastes (cement $\mathrm{C} 1$ ), the $\mathrm{C}_{3} \mathrm{~A}$ content able to adsorb admixture [29] and also able to consume it to form an organic-mineral phase is higher [12, 30]. Consequently, if a high proportion of PCs is adsorbed and consumed by $\mathrm{C}_{3} \mathrm{~A}$, there could be less admixture available in aqueous phase for dispersing the cement grains by adsorption onto their surface [12, 21]. Since slag contains no $\mathrm{C}_{3} \mathrm{~A}$, however, with increasing percentages of the addition and declining cement content, the amount of the $\mathrm{C}_{3} \mathrm{~A}$ able to interact with the admixture during these early stages of hydration likewise decreases. As a consequence, the superplasticizer can be adsorbed directly by the $\mathrm{C}_{3} \mathrm{~S}$ and $\mathrm{C}_{2} \mathrm{~S}$ phases in the cement, leading to the dispersive effect observed. The admixture can also be adsorbed by the slag particles. Prior studies carried out $[20,31]$ on slag and alkali-activated slag (AAS) cements confirm that different types of superplasticizers (naphthalene, melamine and vinyl copolymer based admixtures) can be adsorbed by the slag particles in high alkaline media ( $\mathrm{pH}$ range from 11.7 to 13.6). In particular for naphthalene superplasticizer, even though the amount of admixture adsorbed in AAS pastes was three times lower than in ordinary Portland cement, the decline in yield stress induced was significantly higher for the slag [20]. Such behaviour, again linked to the lack of $\mathrm{C}_{3} \mathrm{~A}$, is consistent with the findings of the present study, where at small dosages of admixture flowability was observed to rise with the slag content. The adsorption isotherms of the PC admixtures on slag-blended cements will be determined in future studies to confirm this behaviour.

Table 7 shows the effect of PC-based admixtures on the plastic viscosity of cement pastes. As a rule, the presence of admixtures in the cement pastes did not notably affect their plastic viscosity or, therefore, the size or number of the agglomerates formed.

\section{Effect of the admixtures on cement hydration processes}

The isothermal conduction calorimetry studies provide information on the exothermal reactions taking place during cement hydration. In addition-free Portland cements, the calorimetric curves exhibit a dormant period associated with a relatively low heat flow. This is followed by a peak at the acceleration period primarily associated with the precipitation of the $\mathrm{C}-\mathrm{S}-\mathrm{H}$ gel and the portlandite generated by alite hydration. The presence of slag in the cement introduced substantial changes in the calorimetric curves (see Fig. 4). Referring to the data in Table 8, the addition of slag to the cement widened the peak associated with hydration product precipitation, an indication that hydration slowed with increasing slag content. The explanation for such delayed hydration in slag cements is that in these blends the slag is activated by the alkaline media generated by the portlandite formed in the hydration of the alite phase $[5,6]$. We also observe that the heat released during cement hydration declines as the slag content rises. These results are in agreement with Richardson et al. [5].

The inclusion of $0.5 \mathrm{mg}$ PC admixture/g binder did not generate meaningful changes in the reactions taking place in cements $\mathrm{C} 1, \mathrm{C} 2, \mathrm{C} 3$ or $\mathrm{C} 4$. However, with $1.0 \mathrm{mg}$ PC admixture/g binder the dormant period was prolonged (see 

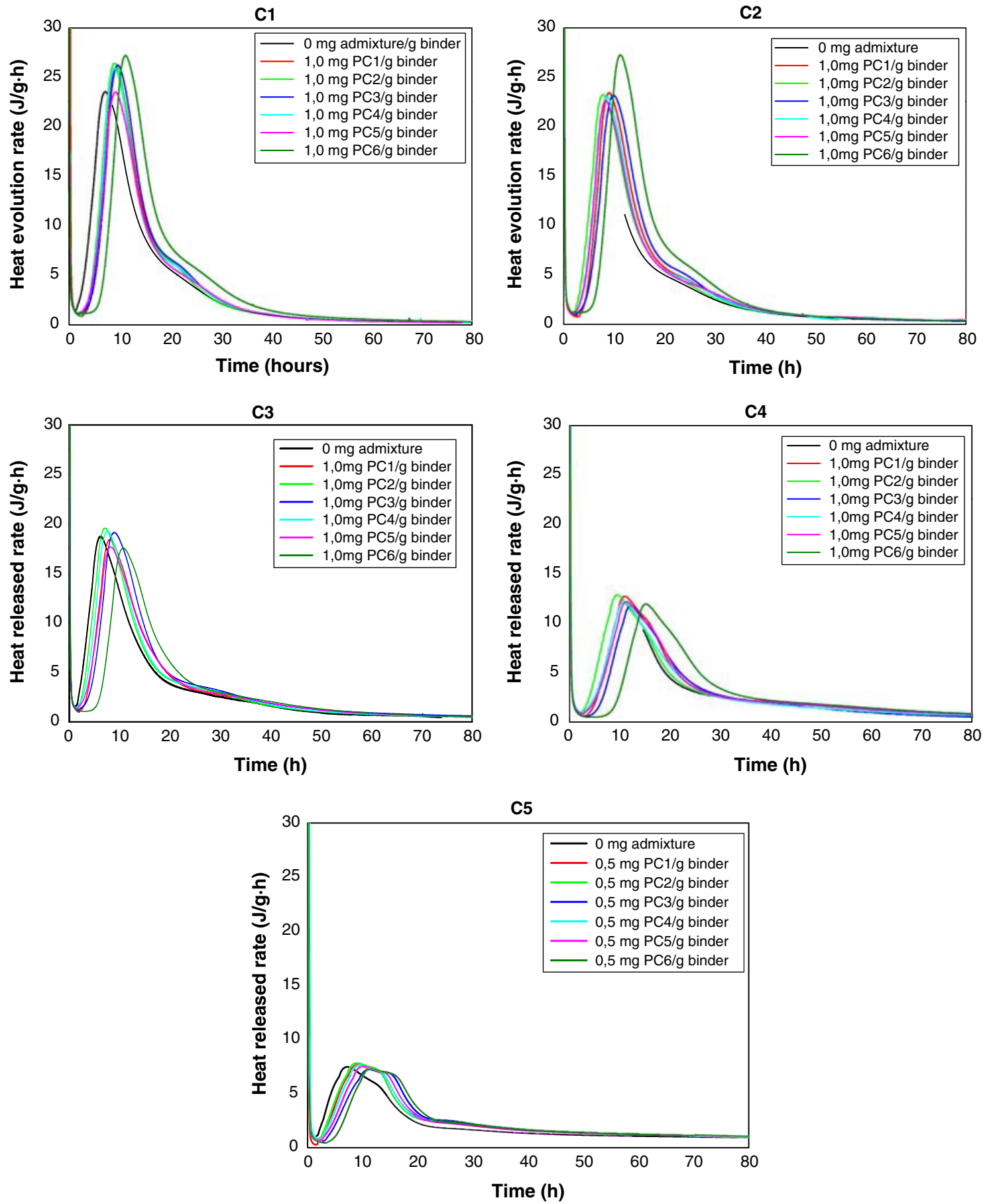

Fig. 4 Heat evolution rate of cement pastes in presence of polycarboxylate-based admixtures

Fig. 4) and the appearance of the peak associated with maximum reaction product precipitation was retarded between 2 and $7 \mathrm{~h}$. Also, the presence of admixtures increases the products precipitation time. By comparison, in cement $\mathrm{C} 5$ pastes, where the admixtures induced greatest dispersion and the highest rise in flowability, the inclusion of only $0.5 \mathrm{mg}$ admixture/g cement retarded the start of the reaction product peak by $2-3 \mathrm{~h}$ and lengthened its duration by 16-17 $\mathrm{h}$ compared to addition-free cement.

This delay in cement hydration in the presence of PCs has been observed by other authors $[9,11]$. The reason of this delay is not completely explained. According to Mollah et al. [32], this delay could be due to three main reasons: (a) the adsorption of the polymer hinders water 
Table 8 Parameters obtained from calorimetric curves shown in Fig. 4

\begin{tabular}{|c|c|c|c|c|c|c|c|c|}
\hline Cement & Admixture & $\begin{array}{l}\text { Peak start } \\
\text { time (h) }\end{array}$ & $\begin{array}{l}\text { Peak max. } \\
\text { time }(\mathrm{h})\end{array}$ & $\begin{array}{l}\text { Max. rate } \\
(\mathrm{J} / \mathrm{g} \mathrm{h})\end{array}$ & $\begin{array}{l}\text { Peak end } \\
\text { time }(\mathrm{h})\end{array}$ & $\begin{array}{l}\text { Peak } \\
\text { duration (h) }\end{array}$ & $\begin{array}{l}\text { Peak heat } \\
\text { released }(\mathrm{J} / \mathrm{g})\end{array}$ & $\begin{array}{l}\text { Heat released } \\
\text { at } 80 \mathrm{~h}(\mathrm{~J} / \mathrm{g})\end{array}$ \\
\hline \multirow[t]{7}{*}{$\mathrm{C} 1$} & $0 \mathrm{mg}$ admixture & 2.1 & 7.9 & 23.2 & 33.4 & 31.3 & 273.1 & 299.9 \\
\hline & $1.0 \mathrm{mg} \mathrm{PC} 1 / \mathrm{g}$ binder & 2.5 & 9.3 & 25.9 & 33.7 & 31.2 & 281.9 & 308.4 \\
\hline & $1.0 \mathrm{mg} \mathrm{PC} 2 / \mathrm{g}$ binder & 2.3 & 9.1 & 26.5 & 32.9 & 30.6 & 281.3 & 311.8 \\
\hline & $1.0 \mathrm{mg} \mathrm{PC} 3 / \mathrm{g}$ binder & 2.1 & 9.7 & 26.3 & 34.8 & 32.7 & 307.5 & 310.0 \\
\hline & $1.0 \mathrm{mg} \mathrm{PC} 4 / \mathrm{g}$ binder & 2.2 & 9.1 & 25.9 & 34.8 & 32.6 & 280.1 & 311.5 \\
\hline & $1.0 \mathrm{mg}$ PC5/g binder & 2.0 & 9.3 & 23.5 & 36.0 & 34.0 & 271.3 & 296.4 \\
\hline & $1.0 \mathrm{mg}$ PC6/g binder & 4.8 & 11.3 & 27.2 & 38.3 & 33.5 & 307.4 & 313.6 \\
\hline \multirow[t]{7}{*}{$\mathrm{C} 2$} & $0 \mathrm{mg}$ admixture & 1.3 & 6.5 & 22.7 & 37.0 & 35.7 & 264.8 & 296.1 \\
\hline & $1.0 \mathrm{mg} \mathrm{PC} 1 / \mathrm{g}$ binder & 3.0 & 9.1 & 23.4 & 36.8 & 33.8 & 267.3 & 270.3 \\
\hline & $1.0 \mathrm{mg} \mathrm{PC} 2 / \mathrm{g}$ binder & 1.8 & 7.8 & 23.2 & 36.9 & 35.1 & 274.8 & 277.0 \\
\hline & $1.0 \mathrm{mg} \mathrm{PC} 3 / \mathrm{g}$ binder & 2.6 & 9.9 & 23.2 & 38.2 & 35.6 & 276.7 & 279.7 \\
\hline & $1.0 \mathrm{mg} \mathrm{PC} 4 / \mathrm{g}$ binder & 2.0 & 8.6 & 23.0 & 36.8 & 34.8 & 267.2 & 296.9 \\
\hline & $1.0 \mathrm{mg} \mathrm{PC} 5 / \mathrm{g}$ binder & 2.3 & 8.4 & 22.6 & 38.4 & 36.1 & 269.1 & 303.9 \\
\hline & $1.0 \mathrm{mg} \mathrm{PC} 6 / \mathrm{g}$ binder & 4.8 & 11.3 & 27.2 & 38.4 & 34.2 & 307.3 & 313.6 \\
\hline \multirow[t]{7}{*}{$\mathrm{C} 3$} & $0 \mathrm{mg}$ admixture & 1.1 & 6.3 & 18.7 & 43.4 & 42.1 & 243.7 & 273.2 \\
\hline & $1.0 \mathrm{mgPC} 1 / \mathrm{g}$ binder & 2.0 & 8.2 & 18.4 & 46.1 & 44.1 & 247.3 & 278.6 \\
\hline & $1.0 \mathrm{mg} \mathrm{PC} 2 / \mathrm{g}$ binder & 1.6 & 7.1 & 19.6 & 41.9 & 40.3 & 249.2 & 282.6 \\
\hline & $1.0 \mathrm{mg} \mathrm{PC} 3 / \mathrm{g}$ binder & 1.8 & 9.0 & 19.1 & 44.2 & 42.4 & 253.9 & 290.1 \\
\hline & $1.0 \mathrm{mg} \mathrm{PC} 4 / \mathrm{g}$ binder & 1.9 & 7.6 & 19.2 & 44.6 & 43.1 & 251.3 & 281.2 \\
\hline & $1.0 \mathrm{mg} \mathrm{PC} 5 / \mathrm{g}$ binder & 1.6 & 8.3 & 17.7 & 46.5 & 42.7 & 246.7 & 276.7 \\
\hline & $1.0 \mathrm{mg}$ PC6/g binder & 4.0 & 10.8 & 17.5 & 48.4 & 44.4 & 244.8 & 272.1 \\
\hline \multirow[t]{7}{*}{$\mathrm{C} 4$} & $0 \mathrm{mg}$ admixture & 1.7 & 8.7 & 13.2 & 55.0 & 53.3 & 234.7 & 265.1 \\
\hline & $1.0 \mathrm{mg} \mathrm{PC} 1 / \mathrm{g}$ binder & 2.5 & 11.0 & 12.7 & 64.0 & 61.5 & 238.7 & 270.8 \\
\hline & $1.0 \mathrm{mg} \mathrm{PC} 2 / \mathrm{g}$ binder & 2.1 & 9.5 & 12.9 & 62.1 & 60.0 & 237.2 & 239.6 \\
\hline & $1.0 \mathrm{mg} \mathrm{PC} 3 / \mathrm{g}$ binder & 3.3 & 12.2 & 11.7 & 61.7 & 58.4 & 236.5 & 239.5 \\
\hline & $1.0 \mathrm{mg} \mathrm{PC} 4 / \mathrm{g}$ binder & 2.6 & 10.8 & 12.2 & 60.1 & 57.5 & 218.8 & 252.2 \\
\hline & $1.0 \mathrm{mg}$ PC5/g binder & 2.7 & 11.3 & 12.2 & 64.2 & 61.5 & 232.2 & 265.3 \\
\hline & $1.0 \mathrm{mg}$ PC6/g binder & 8.1 & 15.2 & 11.9 & 68.0 & 59.9 & 229.8 & 263.0 \\
\hline \multirow[t]{7}{*}{ C5 } & $0 \mathrm{mg}$ admixture & 1.3 & 7.2 & 7.5 & 52.2 & 50.9 & 140.4 & 183.2 \\
\hline & $0.5 \mathrm{mg} \mathrm{PC} 1 / \mathrm{g}$ binder & 1.5 & 9.0 & 7.6 & 69.2 & 67.7 & 172.9 & 202.8 \\
\hline & $0.5 \mathrm{mg} \mathrm{PC} 2 / \mathrm{g}$ binder & 1.7 & 8.9 & 7.8 & 72.7 & 71.0 & 180.9 & 208.2 \\
\hline & $0.5 \mathrm{mg} \mathrm{PC} 3 / \mathrm{g}$ binder & 2.3 & 11.3 & 7.2 & 71.7 & 69.4 & 174.8 & 203.0 \\
\hline & $0.5 \mathrm{mg} \mathrm{PC} 4 / \mathrm{g}$ binder & 2.0 & 9.5 & 7.6 & 69.4 & 67.4 & 172.3 & 201.6 \\
\hline & $0.5 \mathrm{mg} \mathrm{PC} 5 / \mathrm{g}$ binder & 2.0 & 10.01 & 7.5 & 68.2 & 66.2 & 168.8 & 201.2 \\
\hline & $0.5 \mathrm{mg}$ PC6/g binder & 3.3 & 11.6 & 7.3 & 73.4 & 70.1 & 174.4 & 202.4 \\
\hline
\end{tabular}

and therefore $\mathrm{Ca}^{2+}$ ion diffusion between the aqueous phase and the cement, (b) calcium ions form complexes with the polymer, which prevent nucleation and precipitation of hydration products and (c) to the dispersive action of the PC admixtures among the cement grains changes growth kinetics and morphology of hydrate phases.

From Fig. 4, it is observed that PC6 produces in all cement pastes the highest delay of the hydration process. This effect can be due to the fact that this admixture has the greatest charge density (highest carboxylate content) and the adsorption and the surface coverage of cement and slag particles by PC6 is expected to be higher with respect to the other polycarboxylates studied [11]. The higher adsorption of PC6 can hinder the diffusion of water and calcium ions at the cement-solution interface and this induces the greatest delay observed.

The presence of the admixture did not affect heat of hydration in cement pastes $\mathrm{C} 1-\mathrm{C} 4$. Dosages of only $0.5 \mathrm{mg} / \mathrm{g}$ cement of the PC admixtures studied did, however, induce an increase in cement paste C5 heat of hydration. 


\section{Conclusions}

1. Polycarboxylate-based admixtures show higher fluidizing properties in slag Portland cement with respect to non-blended Portland cement. The decrease of the yield stress of cement pastes induced by the PC-based admixtures increases with the slag content.

This effect is mainly due to in non-blended cement pastes, part of the admixture is adsorbed on $\mathrm{C}_{3} \mathrm{~A}$ and also consumed by the $\mathrm{C}_{3} \mathrm{~A}$ phase to form an organicmineral phase, leaving less admixture available in aqueous phase for dispersing the cement grains. However, with increasing percentages of the addition and declining cement content, the amount of the $\mathrm{C}_{3} \mathrm{~A}$ able to interact with the admixture likewise decreases. Consequently, PCs are adsorbed directly onto $\mathrm{C}_{3} \mathrm{~S}$ and $\mathrm{C}_{2} \mathrm{~S}$ and slag particles, inducing their dispersion.

2. The admixtures with highest molecular weight produce the highest reduction of the yield stress of cement pastes due to the highest steric repulsion induced.

3. Polycarboxylate-based admixtures do not modify significantly the plastic viscosity of any of the cement pastes studied.

4. As a consequence of the adsorption of the PCs, a delay of the hydration process of the cement pastes has been observed. The delay is higher in presence of PC6 (with the highest content of carboxylate groups). Additionally, a highest delay of the hydration process is produced in pastes with the highest slag content (75\%).

Acknowledgements Funding for projects BIA 2007-61380 (provided by the Spanish Ministry of Science and Technology (MCyT)) and PMB001389 (CSIC). The authors wish to thank Alice Vieillefosse for help with rheological experiments and Michaela Barbieri, Julien Froidevaux and Matthieu Mottet for help with the zeta potential measurements. Also the authors thank to Dr. Carmen Peinado and Mario Luzón for help with the GPC tests. M. Palacios worked under a postdoctoral contract awarded by the CSIC.

\section{References}

1. Sersale R, Marchese B, Frigione G (1980) In: 7th international congress on the chemistry of cement (edition septima), vol 2. Paris, p 63

2. Moon HY, Kim HS, Choi DS (2006) Constr Build Mater 20:725

3. Mangat PS, El-Khabit JM (1992) Cem Concr Res 22:1089
4. Smolczyk HG (1974) In: 6th international congress on the chemistry of cement, vol 3 (supplementary paper). Moscow, RILEM, Paris, p 57

5. Richardson IG, Wilding CR, Dickson MJ (1989) Adv Cem Res 2(8): 147

6. Escalante-García JI, Sharp JH (2004) Cem Concr Compos 26:967

7. Ohta A, Sugiyama T, Tanaka Y (1997) In: Malhotra VM (ed) 5th CANMET/ACI superplasticizers and other chemical admixtures. Concrete (Canada), p 359

8. Uchikawa H, Hanehara S, Sawaki D (1997) Cem Concr Res 27:37

9. Puertas F, Santos H, Palacios M, Martínez-Ramírez S (2005) Adv Cem Res 17:77

10. Alonso MM, Palacios M, Puertas F, De la Torre AG, Aranda MAG (2007) Mater Constr 57(286):65

11. Winnefeld F, Becker S, Pakusch J, Götz T (2007) Cem Concr Compos 29:251

12. Flatt RJ, Houst Y (2001) Cem Concr Res 31:1169

13. Yamada K, Ogawa S, Hanehara S (2001) Cem Concr Res 31:375

14. Maeder U, Schober I (2003) In: 11th international congress on the chemistry of cement (Durban). South Africa, p 504

15. Chandra S, Björnström J (2002) Cem Concr Res 32:1605

16. Puertas F, Alonso MM, Vázquez T (2005) Mater Constr 55(277):61

17. Rietveld HM (1969) J Appl Crystallogr 2:65

18. Grzeszcyk S, Sudol M (2003) In: 11th international congress on the chemistry of cement (Durban). South Africa, p 727

19. Palacios M, Sierra C, Puertas F (2003) Mater Constr 53(269):89

20. Palacios M, Houst YF, Bowen P, Puertas F (2008) Cem Concr Res (accepted)

21. Perche F (2004) Thése EPFL No 3041, Lausanne. http://library. epfl.ch/en/theses/?nr=3041

22. Zingg A, Winnefeld F, Holzer L, Pakusch J, Becker S, Gaukler L (2008) J Coll Inter Sci 323:301

23. Kerisit S, Cooke DJ, Marmier A, Parker SC (2005) Chem Commun 24:3027

24. Shaughnessy R, Clark PE (1988) Cem Concr Res 18:327

25. Tattersall GH, Banfill PFG (1983) In: The rheology of fresh concrete. Pitman Advanced Publishing Program, London, MA

26. Magarotto R, Torresan I, Zeminian N (2003) In: 11th international congress on the chemistry of cement (Durban). South Africa, p 514

27. Houst Y, Bowen P, Siebold A (2002) In: Dhir RK, Hewlett PC, Csetenvi LJ (eds) Concrete materials and construction. Thomas Telford, London, p 225

28. Houst YF, Bowen P, Perche F, Kauppi A, Borget P, Galmiche L, Le Meins J-F, Lafuma F, Flatt RJ, Schober I, Banfill PFG, Swift DS, Myrvold BO, Petersen BG, Reknes K (2008) Cem Concr Res 38:1198

29. Yoshioka K, Tazawa W, Hawai K, Enohata T (2002) Cem Concr Res 32:1507

30. Plank J, Dai Z, Zouaoui N, Vlad D (2006) In: 8th CANMET/ACI superplasticizers and other chemical admixtures in concrete. Sorrento (Italia), p 201

31. Nägele E, Schneider U (1989) Cem Concr Res 19:811

32. Mollah MYA, Adams WJ, Schennach R, Cocke DL (2000) Adv Cem Res 12:153 